\title{
Evaluation of Mediterranean Type Nutrition Habits with Blood Pressure Regulation and Metabolic Syndrome Parameters in Patients with Hypertension
}

\author{
D Elif Fatma Özkan Pehlivanoğlu, ${ }^{1}$ (1) Yasemin Sağlan, ${ }^{2}$ (1) Hüseyin Balcıoğlu, ${ }^{3}$ \\ (D) Pınar Yıldız, ${ }^{4}$ (D) Uğur Bilge, ${ }^{4}$ (D) İlhami Ünlüoğlu \\ 'Bolu Provincial Health Directorate, Bolu, Turkey \\ ${ }^{2}$ Eskisehir Odunpazari District Health Directorate, Eskisehir, Turkey \\ ${ }^{3}$ Department of Family Medicine, Eskisehir Osmangazi University, Faculty of Medicine, Eskisehir, Turkey \\ ${ }^{4}$ Department of Internal Medicine, Eskisehir Osmangazi University, Faculty of Medicine, Eskisehir, Turkey
}

\section{ABSTRACT}

Objectives: Hypertension is a common chronic disease and a global public health problem. There are many studies showing that the Mediterranean diet has an important role in the prevention of cardiovascular diseases. Our aim in this study is to evaluate the dietary habits of patients with hypertension in Eskisehir and the effects of nutrition on metabolic syndrome and blood pressure regulation.

Please cite this article as:
Özkan Pehlivanoğlu EF, Sağlan

Y, Balcıoğlu H, Yıldız P, Bilge

$U$, Ünlüoğlu İ. Evaluation of Mediterranean Type Nutrition Habits with Blood Pressure Regulation and Metabolic Syndrome Parameters in Patients with Hypertension. Anatol J Family Med 2019;2(3):103-107.

Address for correspondence: Dr. Elif Fatma Özkan

Pehlivanoğlu. Bolu Provencial Health Directorate, Bolu, Turkey

Phone: +90 5378256554

E-mail:

eliffatmaozkan@hotmail.com

Received Date: 18.03.2019

Accepted Date: 11.04.2019

Published online: 13.11.2019

@Copyright 2019 by Anatolian Journal of Family Medicine -

Available online at www.anatoljfm.org

OPEN ACCESS

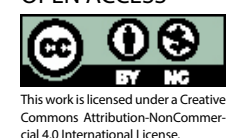

Methods: In this study, 153 volunteer patients with hypertension who applied to Eskisehir Osmangazi University Medical Faculty Hospital Family Medicine and Internal Diseases Clinics were included. The Mediterranean Diet Adherence Screener was used to evaluate the dietary habits of the patients with hypertension.

Results: While the blood pressure regulation rates of patients using adequate levels of olive oil were found to be higher than the patients who did not consume, the body mass indexes of patients with the Mediterranean diet compliance were significantly lower than the patients without diet adaptation. Similarly, considering waist circumference measurements, the median dimensions of the patients with the Mediterranean diet were significantly lower than the patients without Mediterranean diet.

Conclusion: We think that the Mediterranean diet can be regulated as nutrition treatment in the process of protection from cardiovascular diseases and after the formation of the disease by providing appropriate counseling with the specialist branches in a multidisciplinary way, protection can be provided with supportive treatments.

Keywords: Hypertension, metabolic syndrome, diet, mediterranean.

\section{INTRODUCTION}

Hypertension ( $\mathrm{HT}$ ) is a common chronic disease and a global public health problem. Also, it is associated with conditions such as heart disease, stroke, kidney disease, young age death and disability and is a preventable and treatable disease, although it constitutes a significant burden on health and economy. ${ }^{[1]}$ Around one billion people in the world are HT patients. Two-thirds of these patients are in developing countries. It was found that the increase in the average human life time, the increase in metabolic syndrome and obesity, and the excess of salt consumption 
are related with high prevalence of HT. According to World Health Organization (WHO) estimates; approximately $80 \%$ of deaths from cardiovascular diseases can be prevented by controlling some lifestyle factors such as overweight, high blood sugar, abnormal blood lipid levels, and high blood pressure. ${ }^{[2]}$ Considering the recommendations given by the WHO, people should consume more than 400 grams of fruit and vegetables in a day to reduce the risk of chronic diseases, including cardiovascular diseases. ${ }^{[3]}$

The search for different dietary habits and their relationship with chronic diseases provides important information about the place and effectiveness of nutrients. Increasing scientific evidence supports the relationship between dietary factors and long-term health outcomes. ${ }^{[4]}$ There are many studies showing that it has an important role in prevention of cardiovascular diseases. Our aim in this study is to evaluate the dietary habits of HT patients in Eskisehir and the effects of nutrition on metabolic syndrome and blood pressure regulation.

\section{METHOD}

The present study was carried out at the Eskisehir Osmangazi University Medical Faculty Hospital Family Medicine and Internal Diseases Clinics from June 2018 to October 2018. Ethical approval was taken over from Eskisehir Osmangazi University Ethics Committee of Non-Interventional Clinical Researches. In our study, 153 volunteer HT patients who applied to Eskisehir Osmangazi University Medical Faculty Hospital Family Medicine and Internal Diseases Clinics and have not changed their dietary habits in the last year were included. The questionnaire form which was formed by the researchers and The Mediterranean Diet Adherence Screener (MEDAS) was applied to the patients by face to face interview method. MEDAS scale developed for the Primary Prevention of Cardiovascular Diseases with Mediterranean Diet study in 2013 by Martínez-González MÁ, et al. ${ }^{[5,6]}$

There are 14 questions in the scale and each question is scored as 0 or 1 point according to the answer. The total score of the test varies between 0 and 14 points, and the score of 7 and above indicates compliance with the diet. Voluntary primary HT patients who are older than 18 years of age, who are illiterate, women without pregnancy and who have not changed their dietary habits for the last one year, were included in our study. Patients under 18 years of age who are illiterate, pregnant, have changed their nutritional habits in the last year were not included in our study. Semi-Quantitative Nutrition Frequency Questionnaire (FFQ) was used to evaluate routine food intake related to nutrition. ${ }^{[7]}$ To evaluate the blood pressure regulation in patients, the means of one-week blood pressure follow-up were taken and the systolic blood pressure cut-off value was taken as 140 millimeters of mercury $(\mathrm{mmHg})$ and the diastolic blood pressure cut-off value was $90 \mathrm{mmHg} .{ }^{[1]}$ Participants who had moderate dynamic exercise for 5 days/ week and at least 30 minutes/day were considered physically active. ${ }^{[8]}$

In the statistical analysis of data, continuous data are given as mean \pm standard deviation. Categorical data are given as percentage (\%). In the comparison of the groups with normal distribution, independent samples t test analysis was used for the two groups. Pearson Chi-Square, Yates ChiSquare, Pearson Exect Chi-Square and Fisher's Exact ChiSquare analyzes were used to analyze the cross tables. IBM SPSS Statistics V21.0 (IBM Corp. Released 2012. IBM SPSS Statistics for Windows, Version 21.0. Armonk, NY: IBM Corp.) was used to analyze. $P$ value of $<0.05$ was considered as a criterion for statistical significance.

\section{RESULTS}

A total of 153 patients (98 women (\%64.1), 55 men (35.9\%)) were included in the study. The mean age of the participants was $57.1 \pm 11.0$ years, $36(23.5 \%)$ were single and 117 (76.5\%) were married. While $11(7.2 \%)$ of the patients included in the study were literate, 39 (25.5\%) were primary school, 33 (21.6\%) were secondary school, 46 (30.1\%) were high school and 24 (15.7\%) were graduated from university or graduate programs. Of the participants, $12(7.8 \%)$ were civil servants, 21 (13.7) were private sector employees, $2(1.3 \%)$ were workers, 33 (21.6\%) were retired and 85 $(55.6 \%)$ did not work.

When the average of one-week blood pressure follow-up was obtained, 75 (49.0\%) of the participants had their blood pressure regulated while the blood pressure of 78 (51.0\%) was not at the target blood pressure. When the physical activity status of the patients in the study was examined, 55 (35.9\%) were physically active, 98 (64.1\%) stated that they could not perform their physical activities. When the relationship between physical activity and HT was examined, the tension regulation of HT patients who had physical activity was significantly higher than those who did not $(\mathrm{OR}=0.11695 \% \mathrm{Cl}(0.053-0.254) ; \mathrm{p}<0.001) .40(26.1 \%)$ of the participants had diabetes mellitus (DM) and 113 (73.9\%) had no DM. Patients with DM had significantly lower blood pressure regulation than non-DM patients ( $\mathrm{OR}=2.52595 \%$ $\mathrm{Cl}(1.183-5.390) ; \mathrm{p}=0.025)$.

94 (61.4\%) of the $153 \mathrm{HT}$ patients in our study scored 7 and above, and 59 (38.6\%) scored below 7. When Pearson's chi-square test was used, it was found that there was a significant relationship between the median blood pressure regulation and the Mediterranean diet. According to 
the Mediterranean diet, $\mathrm{HT}$ patients have 31.5 times more blood pressure regulation and the blood pressure regulation rate is significantly higher than the ones without diet adaptation ( $\mathrm{OR}=31.50095 \% \mathrm{Cl}(11.281-87.954) ; \mathrm{p}<0.001)$. Food consumption and blood pressure regulation in MEDAS scale parameters is presented in Table 1.

Blood pressure regulation rate was significantly higher in patients who used sufficient olive oil than the ones with low consumption (more than 48 grams per day) $(p<0.001)$. There was no significant difference in the blood pressure regulation rate between HT patients who consumed 2 servings or more of vegetables per day and who did not $(p=0.056)$. There was no significant difference in the rate of blood pressure regulation between HT and consumption of 3 servings of fruit per day or less $(p=0.083)$. There was no statistically significant difference in the rate of blood pressure regulation among patients who consumed 7 glasses or more of wine per week compared to those who consumed less or no consume $(p=0.284)$. There was no statistically significant difference in the rate of blood pressure regulation among patients who had 3 portions or more per week of pulses consumption ( $p=0.643$ ). Body mass indexes of patients with Mediterranean diet compliance (patients who scored 7 or more on the MEDAS scale) were significantly lower than those without dietary compliance $(p=0.007)$. Similarly, considering waist circumference measurements; the median circumference was significantly lower in patients with Mediterranean diet adherence than those without $(p=0.004)$.

\section{DISCUSSION}

Mediterranean cuisine is a kitchen which is a nutritional culture containing rich in olive oil and rich in saturated fats, plenty of fruits, vegetables, cereals, high amounts of pulp, medium amount of fish and chicken (2-4 times a week), low levels of red meat (1-2 times a month) and a small amount of red wine in the meal ( 1 glass a day for women, 2 glasses a day for men). ${ }^{[9]}$ The effects of the dietary habits of the Mediterranean diet have recently become one of the most popular study subjects. The effects of the Mediterranean diet on chronic diseases have become one of the current issues.

In a study, the Mediterranean region was compared with the European region and a lower rate of cardiovascular disease was reported in the Mediterranean region. Cardiovascular events have been shown to be lower in people who consume nutrients such as nuts, olive oil, fruits and vegetables. ${ }^{[10,11]}$ In our study, it was observed that Mediterranean type dietary habits on HT treatment and metabolic syndrome were effective in treatment and weight control. In patients with compliance with the Mediterranean diet, 31.5 times more blood pressure regulation than those without diet adaptation was achieved and blood pressure regulation rates were found to be significantly higher. HT is the main risk factor for cardiovascular diseases and all causes of death. ${ }^{[12]} \mathrm{A}$ healthy lifestyle is a fundamental strategy for reducing $\mathrm{HT}$ and diet is the variable that has the strongest impact on blood pressure. ${ }^{[13]}$ Therefore, we think that the Mediterranean diet is effective in the control of HT.

Omega-3 polyunsaturated fatty acids) consist of fishderived fatty acids (eicosapentaenoic acid and docosahexaenoic acid) and alpha-linolenic acid derived by plant. Although their role in HT is still subject to intense and ongoing scientific debate, it has been shown to have many beneficial effects on cardiovascular diseases. ${ }^{[14]}$ Filipovic MG et al. investigated the relationship between omega-3 and HT that; people with high omega-3 index found that HDL (High Density Lipoprotein) cholesterol levels were

Table 1. Food Consumption and Blood Pressure Regulation in MEDAS Scale Parameters

Blood Pressure Regulation OR $(95 \% \mathrm{CI})$

The use of olive oil as a base oil in meals

More than 48 grams of olive oil consumption per day

Daily red meat consumption below 100 grams

Daily consumption of butter, cream or margarine under 1 portion (12 grams)

Daily under 1 portion (100 milliliters) sugar-sweetened beverage consumption

Having 3 portions and more fish consumption per week

Less than 3 servings per week consumption of pastry

3 servings and more nuts consumption per week

Prefer chicken meat instead of veal
$2.440(1.161-5.127)$

$6.713(3.294-13.682)$

$4.000(1.949-8.210)$

7.143 (3.439-14.835)

2.261 (1.167-4.382)

6.557 (3.235-13.290)

4.556 (2.297-9.038)

3.778 (1.934-7.378)

$5.158(1.830-14.536)$ 
higher than those with low index, whereas triglyceride levels were found to be lower. In a study by Baik et al., ${ }^{[15]}$ it was shown that the consumption of fish and omega fatty acids (each day) decreased the risk of metabolic syndrome by $57 \%$ in men. In our study, 3 portions and more fish consumption per week was found to be effective in HT regulation. In patients with fish consumption of 3 servings per week, blood pressure regulations are provided 6.5 times more than those without consumption.

Olive oil, which is the main oil in the Mediterranean diet, has been stated to contribute to the reduction of obesity in various epidemiological studies. ${ }^{[16]}$ In a study conducted in the Mediterranean diet against obesity and treatment, it has been shown to be beneficial in reducing body fat mass. ${ }^{[17]}$ In our study, HT patients who consumed more than 2 tablespoons ( $48 \mathrm{~g}$ ) of olive oil daily had a 6.7 times higher rate of blood pressure regulation than those without consumption. This shows that olive oil consumption has positive benefits in the treatment of HT. In addition, it is known that people who increase their physical activity will get more positive results. In our study, when the relationship between physical activity and HT was examined, blood pressure regulations were found to be significantly higher than those who did not. It is known that increased therapeutic lifestyle changes will positively affect blood lipid levels. However, some patients may also require drug therapy. ${ }^{[9]}$

\section{CONCLUSION}

In the prevention of metabolic syndrome and chronic diseases, family physicians have important responsibilities in preventive medicine applications. The main approach in the treatment of metabolic diseases such as HT and obesity; providing weight control, increasing physical activity and abandoning sedentary lifestyle. For this purpose; we think that the Mediterranean diet can be regulated as nutrition treatment in the process of protection from cardiovascular diseases and after the formation of the disease and by providing appropriate counseling with the specialist branches in multidisciplinary way, protection can be provided with supportive treatments. Today, despite the many drugs, healthy diet, Mediterranean cuisine and weight control have not changed their impotance in metabolic disease control and they are as effective as monotherapy.

\section{Disclosures}

Peer-review: Externally peer-reviewed.

Conflict of Interest: None declared.

Ethics Committee Approval: The study was approved by the Local Ethics Committee.
Authorship Contributions: Concept - E.F.Ö.P., P.Y.; Design E.F.Ö.P., P.Y.; Supervision - E.F.Ö.P., H.B.; Materials - E.F.Ö.P.; Data collection \&/or processing - E.F.Ö.P., P.Y; Analysis and/or interpretation - Y.S., H.B., E.F.Ö.P.; Literature search - E.F.Ö.P., U.B., I.Ü.; Writing - E.F.Ö.P.; Critical review - E.F.Ö.P., P.Y.

\section{REFERENCES}

1. Arıcı M, Birdane A, Güler K, Yıldız BO, Altun B, Ertürk Ş, et al. Turkish Hypertension Consensus Report. [Article in Turkish]. Turk Kardiyol Dern Ars 2015;43(4):402-9.

2. Tsioufis $C$. The Mediterranean and the DASH Dietary Patterns: Insights into Their Role in Cardiovascular Disease Prevention. Hellenic J Cardiol 2018;59(2):134-5. [CrossRef]

3. WHO. Available at: http://www.who.int/dietphysicalactivity/ en/. Accessed Dec 05, 2019.

4. Mente A, Koning L, Shannon HS. A systematic review of the evidence supporting a causal link between dietary factors and coronary heart disease. Archives of internal medicine 2009;169:7:659-669. [CrossRef]

5. Martínez-González MÁ, Corella D, Salas-Salvadó J, Ros E, Covas MI, Fiol M, et al. Cohort Profile: Design and Methods of the PREDIMED Study. Int J Epidemiol 2012;41(2):377-85. [CrossRef]

6. Schröder H, Fitó M, Estruch R, Martínez-González MA, Corella $D$, Salas-Salvadó J, et al. A Short Screener is Valid for Assessing Mediterranean Diet Adherence among Older Spanish Men and Women. J Nutr 2011;141(6):1140-5. [CrossRef]

7. Hong S, Choi Y, Lee HJ, Kim SH, Oe Y, Lee SY, et al. Development and validation of a semi-quantitative food frequency questionnaire to assess diets of Korean type 2 diabetic patients. Korean diabetes journal 2010;34:1:32-39. [CrossRef]

8. Turkish Endocrinology and Metabolism Society. Hypertension Diagnosis and Treatment Guide 2018.

9. Akbulut G. An Overview of Metabolic Syndrome and Current Approaches in Medical Nutrition Therapy: Review. Turkiye Klinikleri J Cardiovasc Sci 2012;24:231-8.

10. Sofi F, Cesari F, Abbate R, Gensini GF, Casini A. Adherence to Mediterranean Diet and Health Status: Meta-Analysis. BMJ 2008;337:a1344. [CrossRef]

11. Buckland G, González CA, Agudo A, Vilardell M, Berenguer A, Amiano $\mathrm{P}$, et al. Adherence to the Mediterranean Diet and Risk of Coronary Heart Disease in the Spanish EPIC Cohort Study. Am J Epidemiol 2009;170(12):1518-29.

12. WHO. Global Status Report on Non-Communicable Diseases 2014. Switzerland, Geneva:WHO; 2014.

13. Sacks FM, Campos H. Dietary Therapy in Hypertension. N Engl J Med 2010;362(22):2102-12. [CrossRef]

14. Mozaffarian D, Wu JH. Omega-3 fatty acids and cardiovascular disease: effects on Risk Factors, Molecular Pathways, and Clinical Events. J Am Coll Cardiol 2011;58(20):2047-67. [CrossRef] 15. Baik I, Abbott RD, Curb JD, Shin C. Intake of Fish and n-3 Fatty 
Acids and Future Risk of Metabolic Syndrome. J Am Diet Assoc 2010;110(7):1018-26. [CrossRef]

16. Zamora Zamora F, Martínez Galiano JM, Gaforio Martínez JJ, Delgado Rodríguez M. Olive Oil and Body Weight. Systematic Review and Meta-Analysis of Randomized Controlled Trials.
Rev Esp Salud Publica 2018;92. pii: e201811083. [CrossRef]

17. Di Renzo L, Cioccoloni G, Falco S, Abenavoli L, Moia A, Sinibaldi Salimei P, et al. Influence of FTO rs9939609 and Mediterranean Diet on Body Composition and Weight Loss: A Randomized Clinical Trial. J Transl Med 2018;16(1):308. [CrossRef] 